\title{
Analysis of Educational Materials and Destruction/Opt-Out Initiatives for Storage and Use of Residual Newborn Screening Samples
}

\author{
Susanne B. Haga
}

In recent years, the storage and use of residual newborn screening (NBS) samples has gained attention. To inform ongoing policy discussions, this article provides an update of previous work on new policies, educational materials, and parental options regarding the storage and use of residual NBS samples. A review of state NBS Web sites was conducted for information related to the storage and use of residual NBS samples in January 2010. In addition, a review of current statutes and bills introduced between 2005 and 2009 regarding storage and/or use of residual NBS samples was conducted. Fourteen states currently provide information about the storage and/or use of residual NBS samples. Nine states provide parents the option to request destruction of the residual NBS sample after the required storage period or the option to exclude the sample for research uses. In the coming years, it is anticipated that more states will consider policies to address parental concerns about the storage and use of residual NBS samples. Development of new policies regarding storage and use of residual NBS samples will require careful consideration of impact on NBS programs, parent and provider educational materials, and respect for parents among other issues.

\section{Introduction}

$\mathbf{I}$ $\mathrm{N}$ RECENT YEARS, the storage and use of residual newborn screening (NBS) samples has come under growing scrutiny. Likely due in part to enhanced public awareness and concerns about the use of residual NBS samples and recent lawsuits, states have begun to reconsider their policies regarding these issues. Over the past 15 years, several advisory groups and professional organizations have addressed the issue of storage and use of residual NBS spots (Committee on Assessing Genetic Risks, 1994; Therrell et al., 1996; Newborn Screening Task Force, 2000; Association of Public Health Laboratories, 2005; American College of Medical Genetics, 2009). The recommendations have varied, including calling for states to establish policies on the storage and use of residual NBS samples, recommending parental education, and establishing a potential national biorepository.

Residual NBS samples may be stored anywhere from 1 month to an indefinite period (Olney et al., 2006). Most states use residual NBS samples for quality assurance programs and development of new NBS programs (Mandl et al., 2002; Olney et al., 2006), while a smaller proportion allow samples to be used for epidemiological or public health research (Olney et al., 2006). Regardless of how long the samples are stored and for what purpose they may be used, parents may not be informed of these policies as part of state NBS programs. While national advisory groups have called for education of parents about state policies on storage and use of residual NBS samples, most recently by the Secretary's Advisory Committee on Heritable Disorders in Newborns and Children (2010), prior studies indicated that only $11 \%-16 \%$ of states provide this information to parents (Fant et al., 2005; Olney et al., 2006; Therrell et al., 2006). Further, those states that permit use of residual NBS samples for epidemiological research did not always disclose information about these secondary uses to parents (Olney et al., 2006).

To inform ongoing policy discussions, this article provides an update of previous work on the content of educational materials and parental options regarding the storage and use of residual NBS samples. In the coming years, it is anticipated that more states will consider policies to address parental concerns about the storage and use of residual NBS samples. The experiences of states that have implemented new policies regarding storage and use of residual NBS samples will be critical to the expansion of these policies across the United States.

\section{Materials and Methods}

A review of 51 NBS Web sites was conducted for information related to the storage and use of residual NBS samples in January 2010. For each state NBS Web site, general information and information specifically targeted for parents (e.g., brochures, pamphlets, and frequently asked questions

Institute for Genome Sciences and Policy, Sanford School of Public Policy, Duke University, Durham, North Carolina. 
[FAQs]) was reviewed to ascertain if states disclosed the following types of information: (1) storage of residual NBS sample; (2) the length of time of storage of residual NBS sample; (3) use of residual NBS sample for research; (4) types of research residual NBS sample may be used; (5) privacy issues; and (6) options for parents to exclude sample from being used in research or destruction of sample following legally required time for storage. Links to Web sites for state NBS programs were obtained from the National Newborn Screening and Genetics Resources Center (http://genesr-us.uthscsa.edu/resources/consumer/statemap.htm); if links were outdated, an Internet search was conducted to identify the correct URL.

A review of state NBS statutes and bills introduced between 2005 and 2009 regarding storage and use of residual NBS samples was conducted. Several resources were used, including the Genetics Legislation Database maintained by the National Conference of State Legislatures (www.ncsl.org/ default.aspx?tabid=14408), Web sites of state legislatures, and personal communication with state NBS coordinators.

\section{Results}

\section{Sample destruction and opt-out provisions}

Nine states provide parents the option to request destruction of the residual NBS sample after the required storage period or the option to exclude the sample for research uses (Table 1). Six states provide the option to destroy the samples; three also provide the option to remove the samples from research uses. Minnesota provides the option for parents to request the NBS results to be destroyed in addition to the sample. South Carolina provides the option for parents to request the sample be returned to them after the legally required storage period. Missouri has not implemented their new storage/use policy since they did not receive funds requested to initiate the program; they plan to implement the program by 2011 (Sharmini V. Rogers, pers. comm.).

\section{Parental information}

Fourteen states included some information on their Web site (primarily in the parent brochures) about the storage and/ or use of residual NBS samples, about twice as high as previously reported (Olney et al., 2006; Therrell et al., 2006). The study by Therrell et al. (2006) identified eight states that provide information about the status of NBS samples posttesting, six of which were also identified in this study. Table 2 provides a comparison of the different types of information disclosed about the storage and use of residual NBS samples for each of the 14 states. Utah and Nebraska disclose this information to parents even though they do not store residual NBS samples long term. Washington and California provide information about storage and use of residual NBS samples on Web sites describing the privacy policies instead of in the general information materials for parents (e.g., California's Notice of Information and Privacy Practices, www.cdph.ca .gov/programs/nbs/Pages/NBSNPP.aspx). In Pennsylvania, the parent brochure includes a statement regarding use but not storage of samples: "By Pennsylvania law, your baby's blood filter paper test cannot be used for scientific research by any laboratory without your signed permission."

For some states, a discrepancy exists between the information provided in the brochure and the options parents have with respect to storage or use of residual NBS samples. For example, although parents in Maine may request in writing that residual NBS samples not be used for research, this option is not disclosed to them in the brochure or Web site. The state of Michigan offers parents the option of destroying the sample or excluding it from research use, but the parental brochure only describes the option of destroying the sample (though both options are described on Web site).

\section{State statutes}

The issue of storage and/or use of residual NBS samples is currently addressed in statutory law in 10 states (California, Indiana, Iowa, Minnesota, Michigan, Nebraska, Missouri, North Dakota, South Carolina, and Wisconsin). Three states have general privacy legislation relevant to the storage/use of NBS samples (Oregon, Pennsylvania, and Washington). Most of the laws specify time of retention or use of residual NBS samples for research purposes. Missouri is the only state to have revised their law regarding retention time of residual NBS samples, increasing it from 1 month to 5 years. Some

Table 1. Summary of Options to Destroy Residual Newborn Screening Samples OR ExClude FROM RESEARCH (AS OF JANUARY 2010)

Opt-out of research Request to destroy provision sample

Parental request form (URL)

\begin{tabular}{|c|c|c|c|}
\hline California & $x$ & & No form available online; Request to be submitted in writing \\
\hline Iowa & $\times$ & & No form available online; Request to be submitted in writing \\
\hline Maine & $x$ & & No form available online; Request to be submitted in writing \\
\hline Michigan & $\times$ & $\times$ & $\begin{array}{l}\text { www.michigan.gov/documents/mdch/Directive_To_Retain_ } \\
\text { But_Not_Use_DBS_for_Research_Form_revised_2.19.10_ } \\
\text { 314557_7.pdf } \\
\text { www.michigan.gov/documents/mdch/Directive_to_Destroy_ } \\
\text { Form_revised_2.19.10_314558_7.pdf }\end{array}$ \\
\hline Minnesota & & $\times$ & $\begin{array}{l}\text { www.health.state.mn.us/newbornscreening/docs/ } \\
\text { directivedestroy.pdf }\end{array}$ \\
\hline Missouri & $\times$ & $\times$ & www.moga.mo.gov/statutes/c100-199/1910000317.htm \\
\hline South Carolina & $\times$ & $\times$ & $\begin{array}{l}\text { www.scdhec.gov/health/mch/nbs/docs/manual/Blood } \% \\
\text { 20Sample\%20Storage\%20Options.pdf }\end{array}$ \\
\hline Texas & & $x$ & www.dshs.state.tx.us/LAB/NBSdestructionDirective.pdf \\
\hline Washington & & $\times$ & www.doh.wa.gov/ehsphl/phl/newborn/pubs/DestructionRqst.pdf \\
\hline
\end{tabular}


Table 2. Content Analysis of Parent Brochures and State Newborn Screening Web Sites Regarding Storage And Use of Residual Newborn Screening (as of January 2010)

\begin{tabular}{|c|c|c|c|c|c|c|c|c|c|c|c|c|c|c|}
\hline & $M N$ & $M I$ & $M A$ & $N E$ & $S C$ & $T X$ & $W A$ & $W I$ & UT & $I A$ & $C A$ & $P A$ & $V A$ & $M D$ \\
\hline Storage conditions/location & $\times$ & $\times$ & & & $\times$ & & $\times$ & $\times$ & $\times$ & & & & & \\
\hline Time of retention & & & $\times$ & $\times$ & $\times$ & & $\times$ & $\times$ & $\times$ & & & & $\times$ & \\
\hline Potential research use of residual NBS samples & $\times$ & $\times$ & $\times$ & & $\times$ & $x$ & $x$ & & & $x$ & $\times$ & $\times$ & $\times$ & $\times$ \\
\hline Types of research residual NBS sample may be used for & $\times$ & & $x$ & & & $\times$ & & & & & & & & $\times$ \\
\hline $\begin{array}{l}\text { Privacy protections (e.g., de-identification, anonymized, } \\
\text { informed consent) }\end{array}$ & $\times$ & $\times$ & $\times$ & $\times$ & $\times$ & $\times$ & $\times$ & & & $\times$ & $\times$ & $\times$ & $\times$ & \\
\hline Opt-out of research provision & & & & & $\times$ & & & & & $\times$ & $\times$ & & & \\
\hline Option to request destruction of residual sample & $\times$ & $\times$ & & & $\times$ & $\times$ & $\times$ & & & & & & & \\
\hline
\end{tabular}

NBS, newborn screening.

laws authorize the advisory councils for NBS to review (Iowa) or establish (North Dakota) policies. Missouri and California law both allow charging of fees for use of specimens to cover certain expenses.

To determine state policy-makers' interest in establishing laws pertaining to the storage/use of residual NBS samples, a review of state legislation introduced between 2005 and 2009 was conducted. Eleven bills were introduced but not passed or enacted regarding storage and/or use of residual NBS samples in eight states (Table 3). More than half of the bills were introduced in 2010 alone. In general, the bills proposed policies to limit the use of residual NBS samples, provide parents option to request destruction or exclusion of sample from research, and increase parental education and awareness. For example, in 2008, a bill (HF3438/SF3138) was introduced in Minnesota that would have allowed parents to object to uses of residual NBS samples for research purposes (the legislation was vetoed by the governor). In the last legislative session in Minnesota (2008-2009), another bill (HF1341/SF1478) was introduced proposing destruction of all samples within 25 months of birth, unless a parent or legal guardian provided written informed consent to retain the sample (the bill did not reach the floor for a vote) (Amy Gaviglio, pers. comm.). South Carolina has introduced a proviso in their general appropriations bill to suspend the NBS sample storage requirements if there are insufficient state funds to support this activity; if this is to occur, samples would be destroyed in a "scientifically appropriate manner after testing" (H4657).

\section{Discussion}

Residual NBS samples are a rich resource for research studies that require large numbers of samples. The American College of Medical Genetics (2009) and other groups have recognized the substantial value of these samples and advocate for their continued availability to researchers. A number of states have revised or are working toward revision of NBS statutes to address the issues of storage/use of residual samples. In other states, NBS law may be sufficiently broad to allow for the health department and/or the state advisory committee to develop regulations pertaining to storage/use of residual samples, and therefore no statutory revisions are required. Hence, the number of states addressing these issues is likely to be much greater than reported here (Therrell et al., 2006). However, as more states begin to reconsider their policies regarding the storage and use of residual NBS sam- ples, the implications of new policies need to be carefully considered.

Two approaches have been taken by states thus far to address the issue of storage and use of residual NBS samples. As recommended by the Newborn Screening Task Force (2000), some states are raising awareness of current policies through brochures and other resources targeted to parents, thereby increasing transparency and potentially parents' confidence that sample confidentiality is maintained and that samples are only used for approved research purposes as stipulated by law or regulation. For example, in addition to information provided on their NBS Web site, including a form to request destruction of the leftover sample, Minnesota and Texas also include a table of the approved research projects in which residual NBS samples have been used. Some states are informing parents of the policies regarding the storage and use of samples, even if the state does not retain the samples longterm like Utah or permit research uses like Pennsylvania.

A previous survey of NBS resources by Fant et al. (2005) reported that three of five programs informed parents of the secure storage conditions of residual NBS samples and policies regarding use for research purposes. Olney et al. (2006) reported that seven states informed parents that their infants' leftover blood spots may be stored, though they did not specify whether information about the potential use of samples for research was also disclosed. The doubling of states disclosing information about their policies regarding storage and use of residual NBS samples indicates that these issues are being carefully reviewed and educational materials updated accordingly. As the number of states continues to increase, however, standardization of a core set of elements (length of storage time, benefits and risks, privacy protections, research use, etc.) would help facilitate a fair and balanced presentation of these issues overall (Kim et al., 2003; Kharaboyan et al., 2004). For example, the educational materials for parents that describe potential research uses do not always clearly describe the types of research.

Second, in addition to enhanced education, some states now provide the option to destroy or exclude residual NBS samples from research uses (two states offer both options). In Minnesota, parents may also request that the test result be destroyed, whereas other states only provide the option to destroy the sample. If parents request that the test result be destroyed, only the ordering physician would have a copy of the results in the infant's medical record.

A major implication of greater awareness of the storage and use of residual NBS samples is the potential impact on 


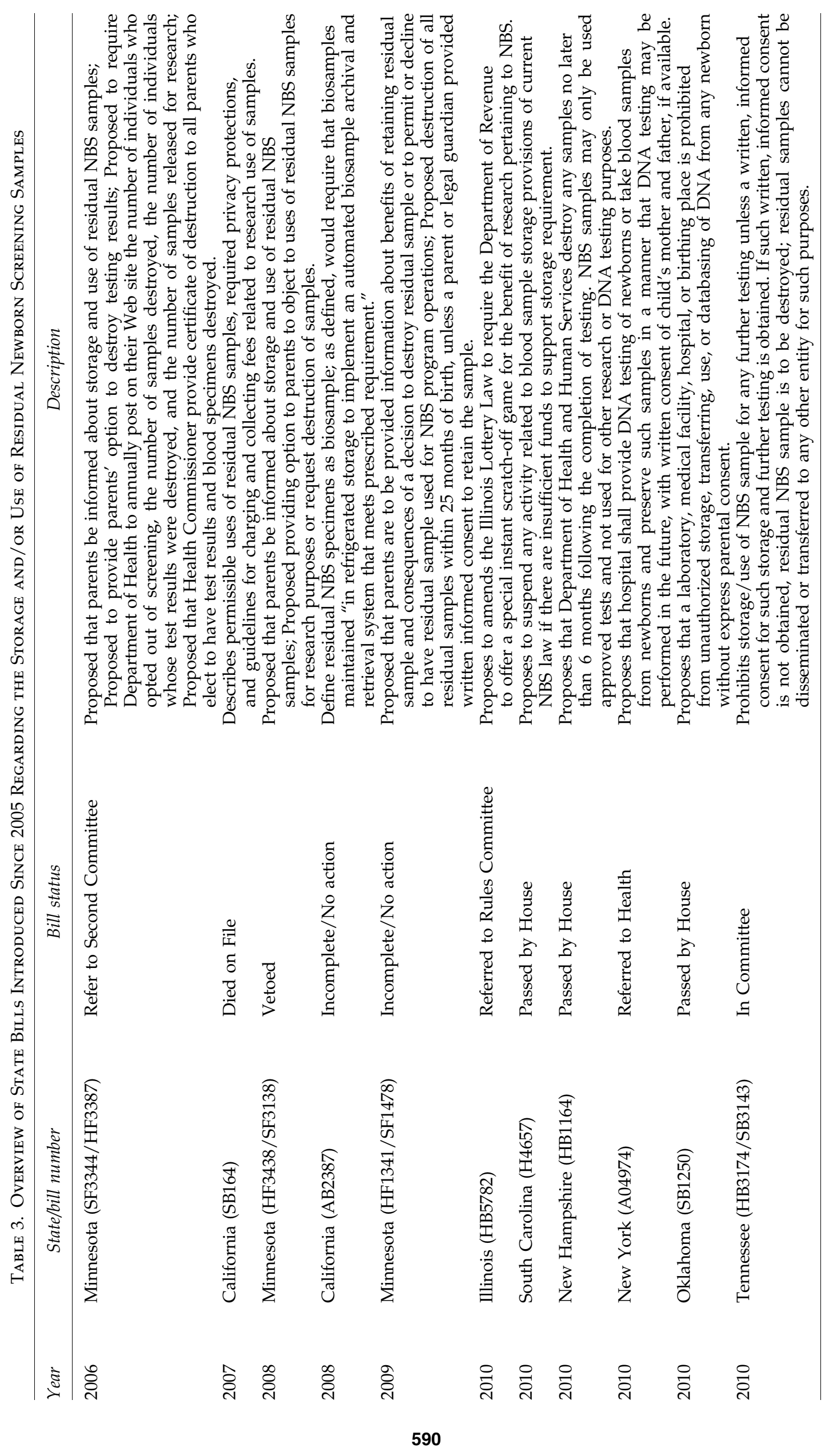


parents' willingness to participate in NBS. Parental fears about inappropriate uses of the leftover samples may outweigh the perceived benefits of NBS, potentially resulting in objections to screening to protect their newborn's privacy. This trade-off of risks and benefits is reminiscent of those decisions made by patients declining medically warranted genetic testing to reduce risk of genetic discrimination (Secretary's Advisory Committee on Genetics, Health, and Society, 2004). However, findings from one study suggest that parents would be agreeable about the storage and use of residual NBS samples if they are informed in advance (Tarini et al., 2009). While NBS population-based research may be justified given the public health benefits of screening and minimal risks (Tarini et al., 2008), the use of a newborn's leftover sample for research not related to NBS seems to fall outside of the program's primary purpose and therefore may be an unreasonable component of the program without disclosure or parental consent. Thus, at the very least, states should specifically disclose their policies about use and storage of residual NBS samples for research other than that related to NBS.

In addition, consideration should be given to providing options to exclude samples from research to minimize adverse impact on the NBS program. Educating parents about the potential uses of residual NBS samples without some type of recourse for parents to opt-out of the research will oblige parents to either agree to all aspects of the NBS program or refuse screening. Some parents may opt to have their newborn screened by a private testing laboratory to prevent the sample from being used in public health research, but this is not an option affordable to all. If parents choose to have their newborn screened by a private laboratory, this will undermine the ability of state laboratories to follow-up with children that test positive, a service covered by the state screening fee. Thus, at a minimum, providing the option to exclude the sample from research may be prudent. Excluding the sample from research uses would preserve the specimen for future testing if needed and involve a minimal amount of cost and labor by health department personnel compared to destruction of the sample.

Early and comprehensive education about NBS should help reduce confusion and allow parents ample time to consider the benefits and risks of long-term storage and use of residual NBS samples. Informing parents at the time of blood spot collection as is typically done (Kim et al., 2003) would likely increase the chances of misunderstanding and decisions harmful to the health of their infant given the short window of time to collect the sample and parents' emotional and physical state. The Newborn Screening Task Force and others have recommended that discussion of NBS and related issues such as storage and use of residual samples should occur during the prenatal period (Newborn Screening Task Force, 2000; Kharaboyan et al., 2004). However, it is unclear which health care provider has the responsibility to inform parents about NBS (Kim et al., 2003). Providers may have various levels of understanding of NBS and policies regarding the storage and use of residual NBS samples. Thus, after defining the appropriate health provider to educate parents, these professionals will need to be provided with the necessary educational resources to discuss the state's screening program and policies.

As states continue to reconsider their policies and educational resources with respect to storage and use of residual
NBS samples, the issues described here and others will need to be carefully considered. States should continue to work toward achieving these goals in consultation with stakeholders representing parents, public health officials, and legal and ethics experts, and learn from states who have already implemented new policies. Continuing the success of NBS programs while respecting the rights of parents is of paramount importance.

\section{Acknowledgment}

Some of the material in this article was presented at the Genetic Alliance's Newborn Screening Summit: Envisioning a Future for Newborn Screening (Dec 7-8, 2009).

\section{Disclosure Statement}

No competing financial interests exist.

\section{References}

American College of Medical Genetics (2009) Position statement on importance of residual newborn screening dried blood spots. Available at www.acmg.net/StaticContent/NewsReleases/ Blood_Spot_Position_Statement2009.pdf, accessed November 23, 2009.

Association of Public Health Laboratories (2005) APHL Position/Policy statement: residual newborn screening (NBS) specimens. Available at www.aphl.org/policy/Documents/ Residual_Newborn_Screening_Specimens.pdf, accessed April 3, 2010.

Committee on Assessing Genetic Risks (1994) Assessing genetic risks: implications for health and social policy. Andrews LB, Fullarton JE, Holtzman NA, Motulsky AG (eds). National Academy Press, Washington, D.C.

Fant KE, Clark SJ, Kemper AR (2005) Completeness and complexity of information available to parents from newbornscreening programs. Pediatrics 115:1268-1272.

Kharaboyan L, Avard D, Knoppers BM (2004) Storing newborn blood spots: modern controversies. J Law Med Ethics 32: 741-748.

Kim S, Lloyd-Puryear MA, Tonniges TF (2003) Examination of the communication practices between state newborn screening programs and the medical home. Pediatrics 111:E120E126.

Mandl KD, Feit S, Larson C, et al. (2002) Newborn screening program practices in the United States: notification, research, and consent. Pediatrics 109:269-273.

Newborn Screening Task Force (2000) Serving the family from birth to the medical home. Newborn screening: a blueprint for the future. Pediatrics 106(2 Pt 2):383-427.

Olney RS, Moore CA, Ojodu JA, et al. (2006) Storage and use of residual dried blood spots from state newborn screening programs. J Pediatr 148:618-622.

Secretary's Advisory Committee on Genetics, Health, and Society (2004) Public perspectives on genetic discrimination, September 2004-November 2004. Available at http://oba.od .nih.gov/oba/sacghs/reports/Public_Perspectives_GenDiscrim .pdf, accessed December 2, 2009.

Tarini BA, Burke W, Scott CR, Wilfond BS (2008) Waiving informed consent in newborn screening research: balancing social value and respect. Am J Med Genet C Semin Med Genet 148:23-30.

Tarini BA, Goldenberg A, Singer D, et al. (2010) Not without my permission: parents' willingness to permit use of newborn 
screening samples for research. Public Health Genomics 13:125-130.

Therrell BL, Hannon WH, Pass KA, et al. (1996) Guidelines for the retention, storage, and use of residual dried blood spot samples after newborn screening analysis: statement of the Council of Regional Networks for Genetic Services. Biochem Mol Med 57:116-124.

Therrell BL, Johnson A, Williams D (2006) Status of newborn screening programs in the United States. Pediatrics 117:S212-S252.

Secretary's Advisory Committee on Heritable Disorders in Newborns and Children (2010) Briefing paper: considerations and recommendations for national guidance regarding the retention and use of residual dried blood spot specimens after newborn screening. Available at www.hrsa.gov/heritable
disorderscommittee/RBSBriefingPaperFINALDraft42310.pdf, accessed July 27, 2010.

Address correspondence to: Susanne B. Haga, Ph.D.

Institute for Genome Sciences and Policy Sanford School of Public Policy

Duke University

450 Research Drive

LSRC, B Wing, Room 320A

Box 91009

Durham, NC 27708

E-mail: susanne.haga@duke.edu 